\title{
Effect of Groundwater Pumping on Seawater Intrusion in Coastal Aquifers
}

\author{
M.M. Sherif ${ }^{1 \star}$ and V.P. Singh ${ }^{2}$ \\ ${ }^{1}$ Civil Engineering Department, College of Engineering, \\ United Arab Emirates University, P.O. Box 17555 Al-Ain, UAE \\ ${ }^{2}$ Civil and Environmental Engineering Department, Faculty of Engineering, \\ Louisiana State University, Baton Rouge, La 70803-6405
}

\author{
تأثير معدلات ضخ المياه الجوفية على تداخل مياه البحر في المناطق الساحلية \\ محسـن شـريف وفيجاي سـنج
}

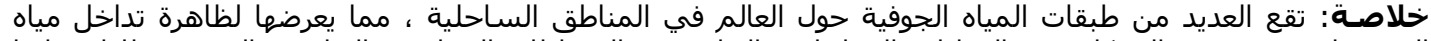

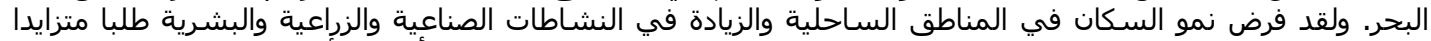

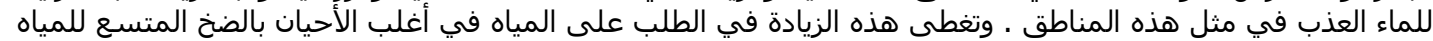

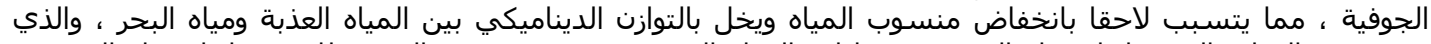

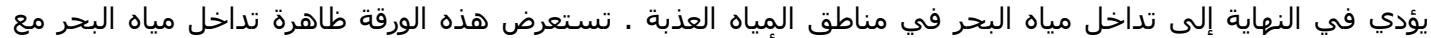

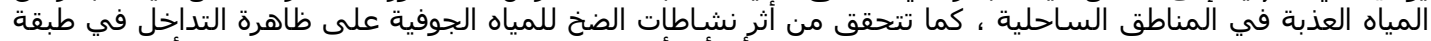

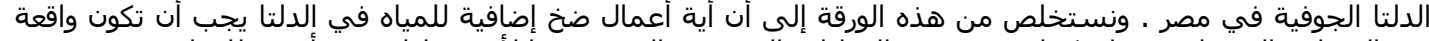

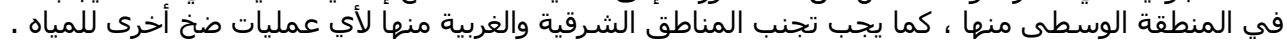

\begin{abstract}
Many aquifers around the globe are located in coastal areas and are thus subjected to the seawater intrusion phenomenon. The growth of population in coastal areas and the conjugate increase in human, agricultural, and industrial activities have imposed an increasing demand for freshwater. This increase in water demand is often covered by extensive pumping of fresh groundwater, causing subsequent lowering of the water table (or piezometric head) and upsetting the dynamic balance between freshwater and saline water bodies. The classical result of such a development is seawater intrusion. This paper presents a review for the seawater intrusion phenomenon in coastal aquifers. The effect of pumping activities on the seawater intrusion in the Nile Delta aquifer of Egypt is investigated. It was concluded that any additional pumping should be located in the middle Delta and avoided in the eastern and western sides of the Delta.
\end{abstract}

Keywords: Seawater intrusion, Groundwater pumping, coastal aquifer, recharge, upcoming, Nile Delta aquifer, SUTRA, watertable.

S eawater intrusion phenomena are of main concern in almost all coastal aquifers around the globe. The problem is more severe in arid and semi-arid regions where the groundwater constitutes the main freshwater resource. A $3 \%$ mixing of seawater with the freshwater in a coastal aquifer would render the freshwater resource unsuitable for human consumption. Therefore, groundwater resources in coastal aquifers should be carefully studied to maintain the dynamic balance between the fresh and saline water bodies.
The shape and degree of the seawater intrusion in a coastal aquifer depend on several factors. Some of these factors are natural and cannot be controlled while others are manmade and could, thus, be managed. These factors, include among others, the type of the costal aquifer (confined, phreatic, leaky, or multi-layer) and its geology and geometry, water table and/or piezometric head, seawater concentration and density, natural rate of flow, capacity and duration of water withdrawal or recharge, rainfall intensities and

*Corresponding author. 


\section{SHERIF AND SINGH}

frequencies, evaporation rates, physical and geometric characteristics of the porous media, geometric and hydraulic boundaries, tidal effects, variations in barometric pressure, earth tides, earthquakes and other vibrational effects, water wave actions, and chemical changes. The depth of the aquifer at the seaside through which the seawater intrudes inland and pumping and recharge rates and locations are the most critical factors to be considered.

Seawater intrusion problems can be simulated both analytically and numerically. Each method has its own advantages and disadvantages as compared to the other. Analytical models are generally simpler in formulation and application and do not require detailed input parameters (data). They provide accurate results when applied to small-scale problems, e.g., upconing phenomenon below pumping wells. However, analytical models often require simplified assumptions and idealized domains. Numerical models are relatively adaptable and flexible and could be applied to heterogeneous systems and irregular domains. Many well-developed and verified numerical codes are already available and can be easily employed to almost every case. The main disadvantage of numerical methods is the need for detailed field data in space and time that might not be available. Analytical solutions are often employed to verify numerical models for idealized domains, flow and boundary conditions.

This paper presents an overview for the mechanism of seawater intrusion in coastal aquifers. The problem is simulated in the horizontal view of the Nile Delta aquifer of Egypt. Different scenarios are made to investigate the effects of pumping activities on the seawater intrusion problem. The USGS model, SUTRA (Voss, 1984), was employed.

\section{Mechanism of Seawater Intrusion}

Consider the idealized leaky system shown in Figure 1. The aquifer is recharged by freshwater entering from the landward boundary and by leakage through the upper clay cap (aquitard) in parts where the free water table is higher than the aquifer piezometric head (before the point of the intersection, hinge point, between the free water table and the aquifer piezometric head). In some cases, the free water table may be higher than the piezometric head all over the upper clay cap, therefore the system will be recharged by the freshwater through out the entire upper boundary as well as the land side boundary. An unconfined (phreatic) aquifer will be recharged by freshwater through infiltration of precipitation. A confined aquifer will be recharged only by freshwater from the boundary at the land side.

At the seaward boundary, there will be an influx of seawater into the system which, because of its greater density, will migrate to the bottom of the aquifer and displace the freshwater. Upward leakage of mixed water will also take place through the aquitard in parts where the free watertable is lower than the piezometric head (near the seaside). The rest of the mixed water will find its way out of the system through the window at the seaside. This discharge through the window and the upward flux through the aquitard cause a loss of salt from the system which is replenished by new seawater moving in from the seaward boundary. The bottom boundary is impermeable. The flux of water and salt ions through this boundary is therefore equal to zero.

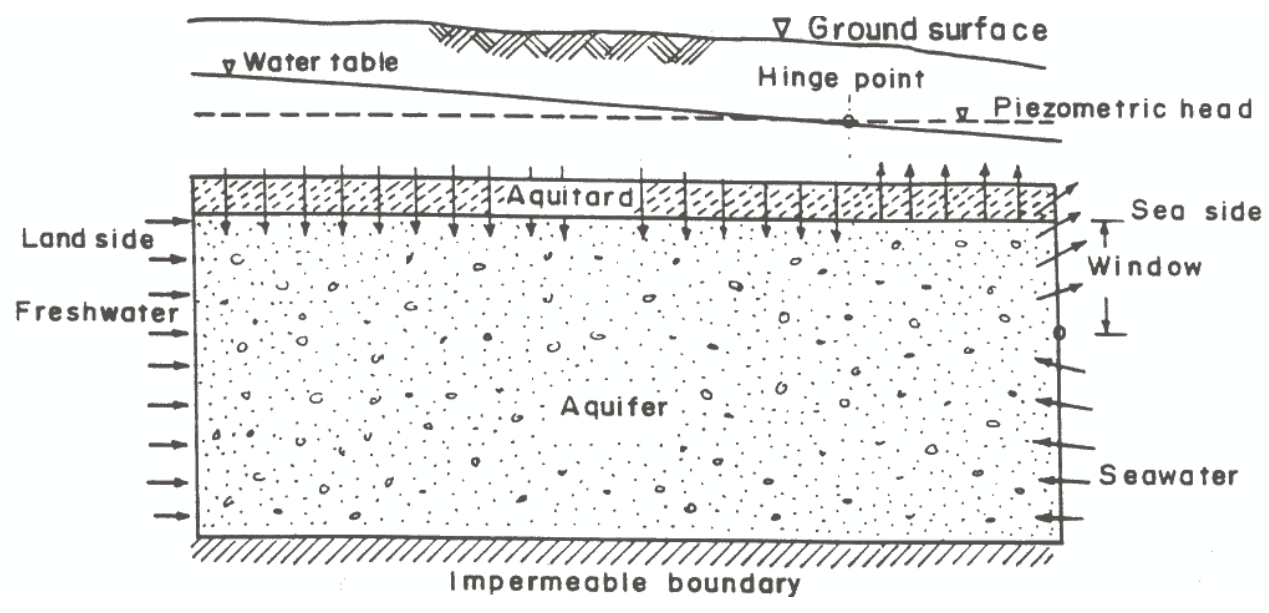

Figure 1. Mechanism of seawater intrusion in coastal aquifers. 
If the boundary conditions remain constant, a state of dynamic equilibrium will eventually be attained by the system. At equilibrium, the total fluid mass entering at both ends of the aquifer plus the leakage influx, will be balanced by the upward leakage through the aquitard plus the flux out through the window on the sea side. Likewise, the salt mass entering at the seaward will be balanced by the salt mass swept out from the system with the mixed water through the aquitard and the window at the seaward boundary.

\section{The Nile Delta Aquifer}

The Nile Delta and its fringes occupy at total area of $22000 \mathrm{~km}^{2}$ (Figure 2). The level of the delta land ranges between $+17 \mathrm{~m}$ above sea level at the south boundary to less than one meter at the north boundary (Farid, 1985).

The Nile Delta aquifer is naturally bounded northward by the Mediterranean Sea and eastward by the Suez Canal. The western boundary extends well into the desert. At the south, the aquifer demises and seems to be isolated from the aquifer of Upper Egypt by an aquiclude approaching the clay cap near Cairo.

Many studies have been conducted to assess seawater intrusion in the Nile Delta aquifer using numerical techniques. The simulations have been mainly two-dimensional either in the vertical cross section or in the horizontal view. Some studies were based on the sharp interface approach, while others accounted for the dispersion zone and density variation in the vertical direction. Previous investigations that adopted the sharp interface approach include Wilson et al. (1979), Amer and Farid (1981), and Farid (1980 and 1985). Contour lines for the freshwater thickness in the aquifer were outlined.

Sherif et al. (1988, 1990), Amer and Sherif (1995), Sherif and Singh (1997), and Sherif (1999) conducted various investigations to study the seawater intrusion problem in the Nile Delta aquifer using the dispersion zone approach. Based on numerical simulations, equiconcentration and equipotential lines were drawn to characterize the flow pattern and salinity distribution.

\section{Hydraulic Parameters and Pumping Activities}

Field and laboratory experiments were carried out to determine the hydraulic parameters for the Nile Delta aquifer. Based on field data, an isotropic hydraulic conductivity of $100.0 \mathrm{~m} /$ day and a storativity of about $10^{-4}$ to $10^{-3}$ were considered representative of the regional values of the aquifer. Farid (1980) reported different values for hydraulic conductivity and storativity at various locations. The hydraulic conductivity of the

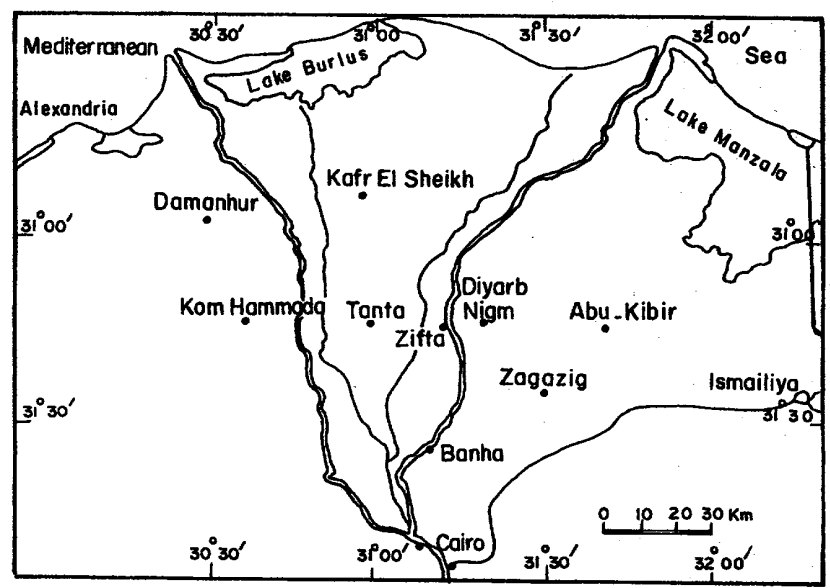

Figure 2. The Nile Delta aquifer in Egypt.

aquifer decreased toward the south and west. An effective porosity of 0.3 was considered to represent the aquifer medium.

The clay cap takes different profiles along the shore of the Mediterranean Sea. Generally, it is divided into two layers. The first layer is the upper clay cap that acts as an aquitard, about $20 \mathrm{~m}$ thick. The second layer is the lower clayey sand layer, a few meters in thickness, with a higher permeability than the former. The thicknesses of the upper clay cap (aquitard) and the clayey sand layer are well defined at many locations in the Delta. Their thicknesses are mostly less than $20 \mathrm{~m}$ and $15 \mathrm{~m}$, respectively. Only along the Mediterranean shore, the thickness of the clay cap may reach $70 \mathrm{~m}$.

The vertical movement of water through the upper semipervious layer affects, to a great extent, the water balance of the system. The downward movement of water occurs in two different stages. The first is the downward infiltration of irrigation water from the ground surface to the subsoil water table through the unsaturated zone of the clay cap. The velocity of this movement is defined by the downward infiltration velocity. The second is the movement of the subsoil water from the water table to the groundwater in the aquifer through the saturated zone of the clay cap. The velocity of the flow in this zone is defined by the seepage velocity and can be evaluated from Darcy's law. The vertical hydraulic conductivity, $\mathrm{K}_{\mathrm{cv}}$, for the clay layer in the Nile Delta has an average value of 2.5 $\mathrm{mm} /$ day. Based on similar studies, the longitudinal dispersivity, $\alpha_{\mathrm{L}}$, and lateral dispersivity, $\alpha_{\mathrm{T}}$, for the Nile Delta aquifer are set equal to $100 \mathrm{~m}$ and $10 \mathrm{~m}$, respectively. The free watertable is measured at various locations. When this information is missing it is generally assumed to be $1.0 \mathrm{~m}$ below the ground surface. The piezometric head is measured periodically through an intensive-monitoring network. Records for water levels and piezometric heads are available in the 


\section{SHERIF AND SINGH}

database of the Groundwater Research Institute (GWRI), National Water Research Center (NWRC), Egypt. Pumping activities from different governorates are monitored by the GWRI in Egypt. Total pumping from the Nile Delta is estimated at 2.3 billion $\mathrm{m}^{3} /$ year.

\section{Selected Pumping Scenarios}

To examine the response of the Nile Delta aquifer to pumping activities and define the best locations for additional groundwater pumping, six different scenarios of pumping were selected and compared with the current pumping (Basic run). The simulation was preformed via SUTRA to reflect the intrusion behavior in the aerial view. These scenarios were chosen after many preliminary simulations with coarser grid systems. The Delta was divided into three main zones for pumping activities; the middle zone, the eastern zone, and the western zone. The following scenarios were thus considered:

Basic Run: This scenario represented current pumping activities (2.3 billion $\mathrm{m}^{3} /$ year) from the various governorates in the Nile Delta.

Scenario 1: The current pumping was redistributed in the eastern and western sides of the Delta without any pumping from the middle of the Delta. The 2.3 billion $\mathrm{m}^{3} /$ year were distributed among the nodal points in the eastern and western Delta only.

Scenario 2: The 2.3 billion $\mathrm{m}^{3} /$ year were pumped from the middle Delta only without any pumping in the eastern and western sides.

Scenario 3: In this scenario, the current pumping was doubled; 4.6 billion $\mathrm{m}^{3} /$ year were pumped from the same governorates. The share of each node, as calculated in the basic run was thus doubled.

Scenario 4: In this scenario, 4.6 billion $\mathrm{m}^{3} /$ year were pumped from the eastern and western sides of the Delta. No pumping takes place in the middle Delta.

Scenario 5: The distribution of the current pumping ( 2.3 billion $\mathrm{m}^{3} /$ year) was maintained, while additional pumping of 1.5 billion $\mathrm{m}^{3} /$ year in the eastern Delta and 0.8 billion $\mathrm{m}^{3} /$ year in the western Delta were considered. The total pumping was thus equal to 4.6 billion $\mathrm{m}^{3} /$ year.

Scenario 6: In this scenario, an additional pumping of 2.3 billion $\mathrm{m}^{3} /$ year was considered in the middle Delta only, while the distribution of the current pumping was maintained.

\section{Results and Discussion}

The USGS model, SUTRA, was employed to simulate the seawater intrusion behavior under the selected scenarios. To initiate the numerical calculation, for the basic run, a fresh water concentration and a hydrostatic pressure distribution between Cairo and the Mediterranean Sea were assumed through the entire domain. For the other scenarios (1 through 6) the concentration and pressure distribution resulting from the basic run were considered as initial conditions. The convergence criterion for both the concentration and the pressure was set equal to $10^{-3}$.

The model was first run under transient conditions for both water flow and transport of salt. The time step was set equal to 3.65 days. Hundreds of years were required to reach steady state conditions through the transient procedure. Results of the concentration distribution and piezometric heads were stored after every 1000 time steps (10 years) and compared to each other after every 2000 time steps. Overlapping the equiconcentration lines indicated that the rate of seawater intrusion migration or retardation under any of the proposed scenarios was relatively small, in the range of 10 to $40 \mathrm{~m} /$ year. A movement of $1.0 \mathrm{~km}$ of any equiconcentration line would require between 25 and 100 years, according to the proposed scenario.

Figure 3 shows the equiconcentration lines under the current pumping activities at the steady state conditions. Equiconcentration line 31.5 (31,500 ppm) intruded inland to a distance of $41.0 \mathrm{~km}$ measured along latitude $31^{\circ} 00^{\prime}$ from the shore boundary, while equiconcentration line 17.5 intruded to a distance of $61.5 \mathrm{~km}$ along the same latitude measured from the sea side boundary. Equiconcentration line 3.5, representing 0.1 of the maximum concentration, intruded inland to a distance of $84 \mathrm{~km}$.

Although no exact measurements for the concentration distribution in the Nile Delta aquifer are available, yet the above concentration resulted from the simulation of the current conditions is quite consistent with the observations recorded from production wells in the region. For example, the salinity of groundwater

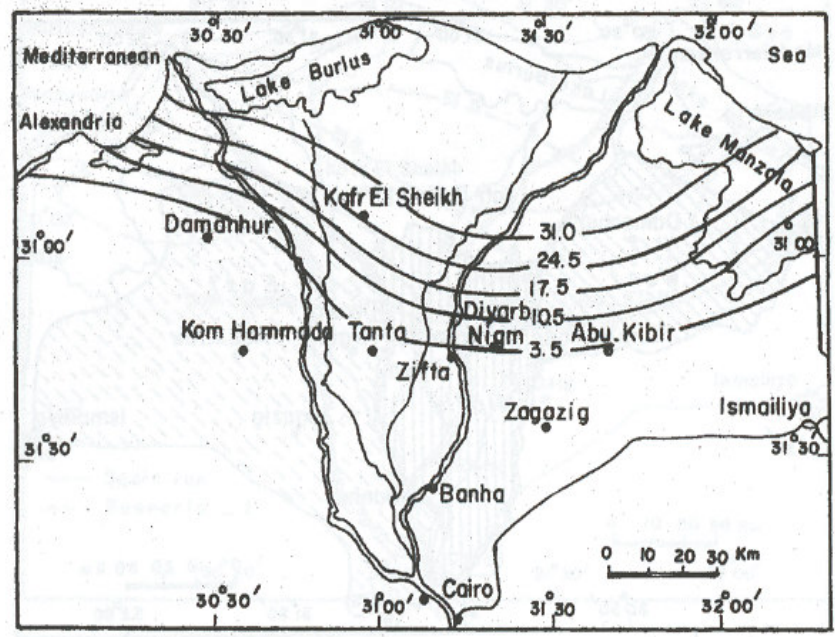

Figure 3. Equiconcentration lines under the current pumping activities. 
at Kafr El-Sheikh, $53 \mathrm{~km}$ from the shore line, is equal to the seawater salinity at a depth of less than $100 \mathrm{~m}$. On the other hand, the groundwater at Tanta, $92 \mathrm{~km}$ from the shore line, is mostly fresh up to a depth of about $250 \mathrm{~m}$. To the south of Tanta, the groundwater has a salinity of less than 1000 ppm throughout the entire depth of the aquifer.

It should also be noted that while areal simulation of seawater intrusion in the Nile Delta aquifer is very useful in testing intrusion behavior under various scenarios of pumping, it does not provide accurate values for concentration distribution. The salinity may vary in the vertical direction, at the same point, from fresh water concentration to seawater concentration. This variation can not be included in the areal simulation. The concentration of groundwater at a specific point in the plane is not indicative unless the depth of that point is defined.

Under Scenario 1, where the current pumping is redistributed to the eastern and western zones of the Delta, less intrusion was encountered in the middle and more intrusion is found in the eastern and western parts. Equiconcentration lines in the eastern zone were slightly affected. In the middle, all equiconcentration lines retreated to the sea side.

Under Scenario 2, where current pumping (2.3 billion $\mathrm{m}^{3} /$ year) is only considered to take place in the middle Delta, less intrusion is found as compared to the basic run. In the middle Delta, all equiconcentration lines retreated backward to the sea side within a few kilometers (1 to $4 \mathrm{~km}$ ), while they retreated by some tens of kilometers (20 to $30 \mathrm{~km}$ ) in the eastern parts. This may be attributed to the proximity of the Nile river to the pumping areas and the high recharge rate resulting from intensive irrigation.

Under Scenario 3, the current pumping was doubled from the same locations. At steady state conditions, various equiconcentration lines advanced by considerable distances as compared to the current conditions (basic run). The eastern parts of the Delta were much more affected than the others.

Under Scenario 4, 4.6 billion $\mathrm{m}^{3}$, were pumped annually from the eastern and western zones only. Equiconcentration lines in the western area advanced inland considerably. Compared to the basic run, equiconcentration line 31.5 advanced by a distance of 17 $\mathrm{km}$ measured along latitude $30^{\circ} \quad 30^{\prime}$, while equiconcentration line 3.5 advanced $3.5 \mathrm{~km}$ along the same latitude. In the middle Delta, all equiconcentration lines retreated to the sea side, while more seawater intrusion was observed in the eastern Delta.

In Scenario 5, where additional pumping of 1.5 and 0.8 billion $\mathrm{m}^{3} /$ year were considered from the eastern and western Delta, respectively, the seawater traveled inland in the entire domain with the exception of a limited area in the far east.
Under Scenario 6, an additional pumping of 2.3 billion $\mathrm{m}^{3} /$ year was considered in the middle Delta. Limited additional intrusion was seen as compared to the basic run. At steady state conditions, maximum inland migration of $4.0 \mathrm{~km}$ was encountered in the middle Delta. Equiconcentration lines in the western Delta moved inland by variable distances between 1 and $3 \mathrm{~km}$. In the eastern Delta, equiconcentration line 3.5 retreated to the sea side by about $8.0 \mathrm{~km}$, while equiconcentration line 31.5 was not affected as compared to the basic run.

Figures $4 \mathrm{a}$ through $\mathrm{f}$ compare equiconcentration lines 31.5 and 3.5 in the various scenarios with those in the basic run (representing the current conditions). Solid lines represent the basic run, while dashed lines represent various scenarios as indicated. The distance between the former two equiconcentration lines may be considered to indicate the width of the dispersion zone.

Scenarios 1 and 2, consider current pumping but with different allocation to pumping area. Figures $4 \mathrm{a}$ and $b$ reveal that both of these two scenarios are actually better than the current policy for groundwater pumping as regard to seawater intrusion. Although the same amounts of water were pumped, yet less intrusion was encountered. Scenario 1 reduces the intrusion in the middle considerably with an additional slight inland intrusion in the east and more intrusion in the west. Scenario 2 reduces the intrusion throughout the Delta with much more effect in the eastern parts.

Scenarios 3, 4, 5, and 6 represent seawater intrusion under various policies of pumping an additional amount of 2.3 billion $\mathrm{m}^{3} /$ year. Figures $4 \mathrm{c}$ through $f$ reveal that scenarios 4 and 6 are causing less impact.

In Scenario 4, Figure 4d, although the pumping from the entire Delta was doubled yet less intrusion was found in the middle Delta. On the other hand, equiconcentration line 3.5 advanced inland by a distance of about $21 \mathrm{~km}$ and $7.5 \mathrm{~km}$ in the western and eastern parts, respectively.

Under Scenario 6, where additional pumping of 2.3 billion $\mathrm{m}^{3} /$ year is considered from the middle Delta only, equiconcentration line 3.5 advanced inland by a limited distance in the middle and western Delta and retreated slightly in the eastern Delta as shown in Figure 4f. Scenario-6 is thus more relevant and has nominal impact on the groundwater quality.

\section{Conclusions}

The Nile Delta aquifer is severely subject to the problem of saltwater intrusion from the Mediterranean Sea. This has a serious environmental impact. Groundwater resources should thus be carefully managed and developed. 


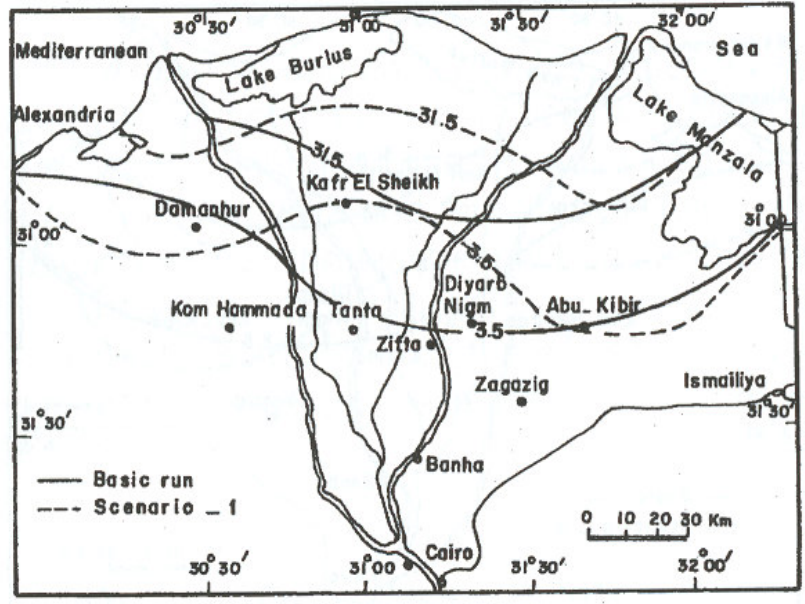

a. Basic run versus Scenario 1 .

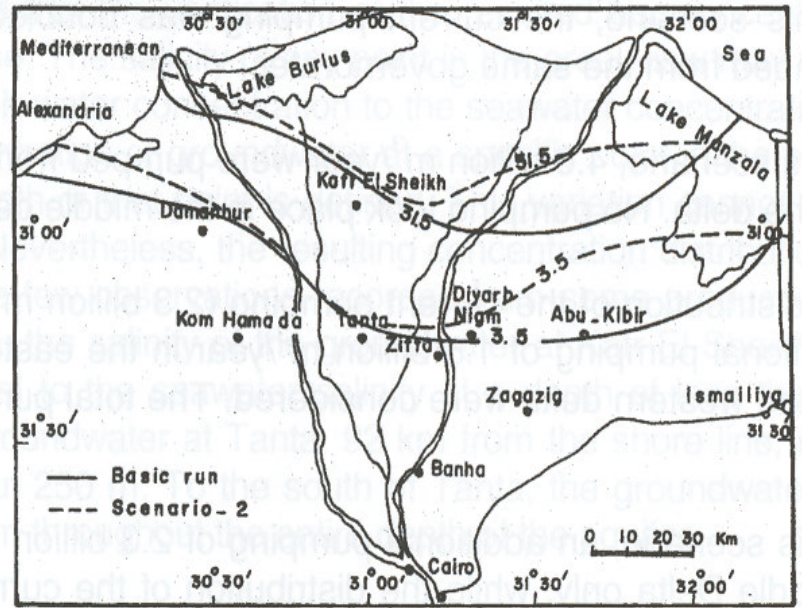

b. Basic run versus Scenario 2 .

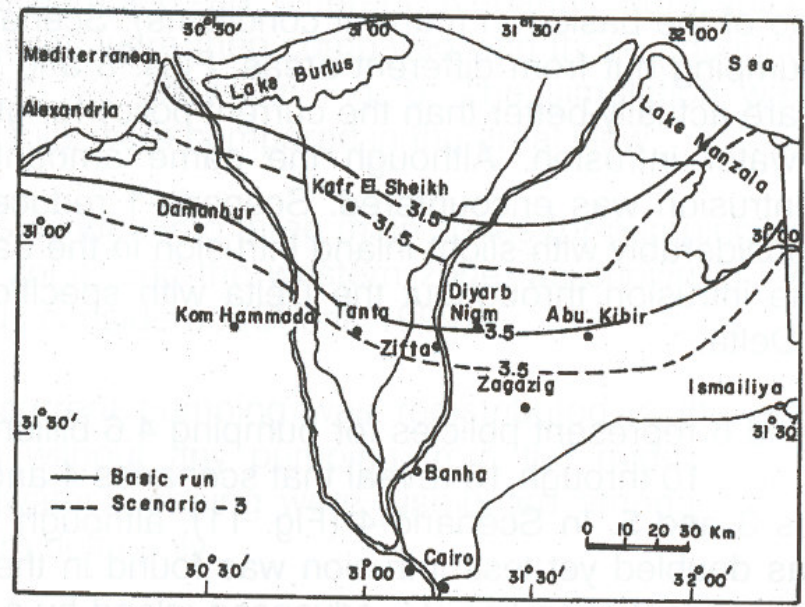

c. Basic run versus Scenario 3 .

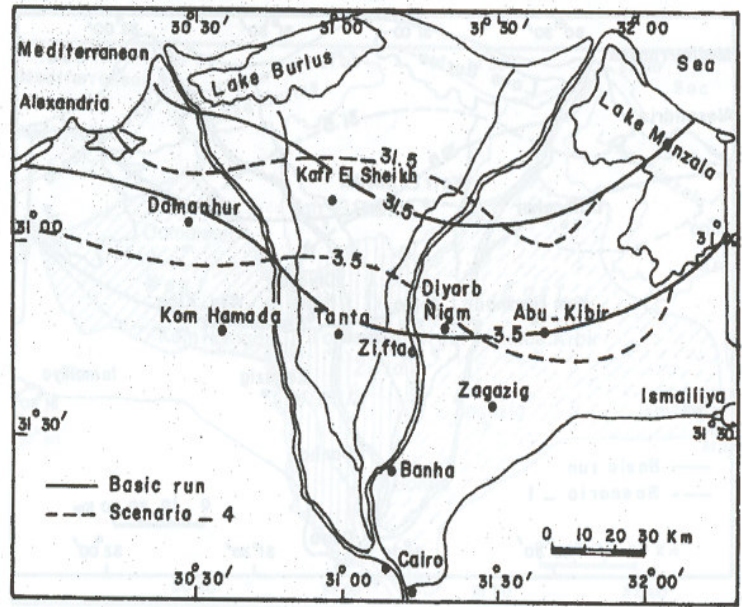

d. Basic run versus Scenario 4 .

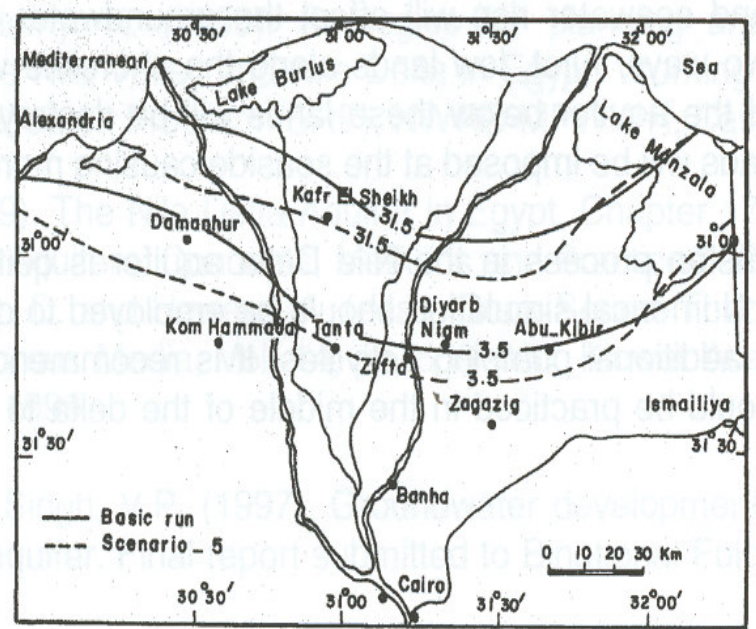

e. Basic run versus Scenario 5 .

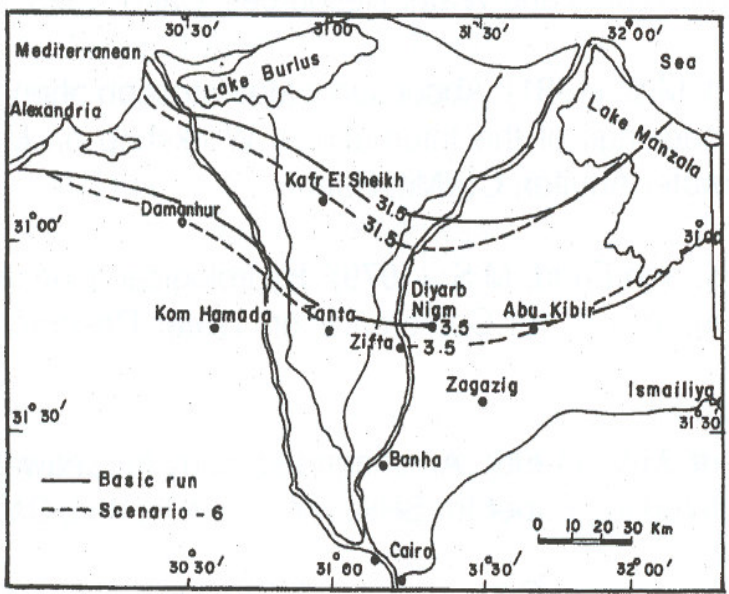

f. Basic run versus Scenario 6 .

Figure 4. Comparison between equiconcentartion lines of the basic run and other scenarios. 
To examine the response of the Nile Delta aquifer under different pumping activities, six scenarios were considered and the resulted intrusion was compared with the original one under current pumping conditions. Two alternatives for the amount of groundwater pumping were thus examined; 2.3 and 4.6 billion $\mathrm{m}^{3} /$ year. For the two alternatives different locations for pumping were checked and the resulted seawater intrusion was assessed for the different cases and compared with the intrusion under the current pumping conditions.

For the first alternative, Scenario 2 is the best. All equiconcentration lines were retreated throughout the entire Delta with much more effect in its eastern and western parts. For the second alternative, where 4.6 billion $\mathrm{m}^{3} /$ year were pumped, Scenario 6 has the least impact amongst the tested scenarios. All tested scenarios indicated that any additional pumping should be practiced from the middle Delta and minimized in the eastern and western parts of the Delta.

\section{Acknowledgement}

This study was sponsored by the Binational Fulbright Commission in Egypt. Several constructive ideas and remarks were made by members of the Fulbright Commission during the course of the study. The UAEU provided the support and facilities to complete this paper.

\section{References}

Amer, A. and M. Sherif. 1995. Behavior of seawater intrusion in the Nile Delta under different conditions. Working Paper Series No. 32-1, SRP, NWRC-MPWWR, Cairo, Egypt.

Amer, A. and M.S. Farid. 1981. About sea water intrusion phenomenon in the Nile Delta aquifer. Proceedings of the International Workshop on Management of the Nile Delta Groundwater Aquifer, CU/Mit, Cairo.

Farid, M.S. 1980. Nile Delta ground water study. M Sc. Thesis, Faculty of Engineering, Cairo University, Cairo.

Farid, M.S. 1985. Management of groundwater system in the Nile Delta. $\mathrm{Ph}$. D. Thesis, Faculty of Engineering, Cairo University, Cairo.

Sherif, M.M. 1999. The Nile Delta aquifer, Chapter 17. Seawater Intrusion in Coastal Aquifers: Concepts, Methods and Practices, Bear et. al. (eds). Book Series Theory and Application of Transport in Porous Media, Vol. 14, pp. 559-590, Kluwer Academic Publishers, Netherlands.

Sherif, M.M. and V.P. Singh. 1997. Groundwater development and sustainability in the Nile Delta aquifer. Final Report, Binational Fulbright Commission, Egypt.

Sherif, M.M., V.P. Singh, and A.M. Amer. 1988. A two-dimensional finite element model for dispersion (2D-FED) in coastal aquifers. $J$. Hydrol. 103:11-36.

Sherif, M.M., V.P. Singh, and A.M. Amer. 1990. A sensitivity analysis of (2D FED), a model for sea water encroachment in leaky coastal aquifers. J. Hydrol. 103:11-36.

Voss, C.I. 1984. A finite element simulation model for saturatedunsaturated, fluid density-dependent ground-water flow with energy transport or chemically-reactive single-species solute transport. Water Resources Investigation Report 84-4369, USGS, USA.

Wilson, J., H. Townley, and A. Sada Casta. 1979. Mathematical development and verification of a finite element aquifer flow model AQUIFEM-1. Technology Adaptation PRPGRAM Report No. 792, MIT, Cambridge.

Received September 2002.

Accepted November 2002. 